\title{
Sobre um foco urbano de esquistossomose em área metropolitana da reqião sudeste do Brasil
}

\section{Urban focus of schistosomiasis in a metropolitan area in South-eastern Brazil}

\author{
Carlos Tito Guimarāes*, Cecília Pereira de Souza*, Omar dos Santos Carvalho*, Naftale Katz*
}

\begin{abstract}
GUIMARÃES, C.T. et al. Sobre um foco urbano de esquistossomose em área metrpolitana da região sudeste do Brasil - Rev. Saúde Pública, 27: 210-3, 1993. Descreve-se foco de transmissão ativa de esquistossomose mansoni em Belo Horizonte, MG, Brasil, localizado no Parque "Julien Rien", uma área de lazer com $48.500 \mathrm{~m}^{2}$, criada pela Prefeitura Municipal, em 1980, na zona sul da cidade. Em capturas feitas durante 10 anos (1983-1992) foram coletados 3.361 exemplares de Biomphalaria glabrata (diâmetro médio= 9,3 mm), dos quais $23(0,7 \%)$ estavam infectados pelo Schistosoma mansoni. O encontro de moluscos hospedeiros intermediários do $S$. mansoni em áreas urbanizadas (pequenos lagos artificiais cimentados de parques, jardins, prédios públicos, e outros) pode estar relacionado com a introdução de peixes e plantas aquáticas. É sugerida, como medida profilática, a não introdução de peixes e plantas aquáticas nesses locais, a não ser após período de quarentena de, no mínimo, 30 dias.
\end{abstract}

Descritores: Biomphalaria, parasitologia. Schistosoma mansoni. Esquistossomose mansônica, transmissão. Urbanização.

\section{Introduçáo}

Classificada como "endemia rural", a esquistossomose é encontrada hoje na periferia e mesmo dentro das grandes cidades, como nos casos de Fortaleza, CE, Salvador, BA e em Belo Horizonte, MG, onde as bacias hidrográficas do Ribeirão do Arrudas e do Lago da Pampulha têm, ao longo dos anos, sido responsáveis pơr milhares de casos dessa helmintose $e^{4,6,7,9}$.

Os primeiros relatos sobre a ocorrência de moluscos hospedeiros intermediários do Schistosoma mansoni, em Belo Horizonte, datam de 19377 . Em 1953 foi feito o primeiro levantamento malacológico naquela cidade ${ }^{8}$, o que foi repetido em $1967^{10}$. Em 1981, Souza e col. ${ }^{11}$, após extenso levantamento na citada cidade, concluíram ter ocorrido uma redução de mais de $50 \%$ dos criadouros identificados, em 1967, em decorrência do processo de urbanização verificado nos bairros mais centrais, o que não ocorreu na periferia onde a esquistossomose continuava endêmica. Entretanto, a partir de 1983 , começaram a ocorrer capturas de moluscos naqueles bairros mais centrais e em locais que fugiam aos padrões

Centro de Pesquisas René Rachou/FIOCRUZ - Belo Horizonte, MG - Brasil

Separatas/Reprints: C. T. Guimarães - Caixa Postal 1743 . 30161-970 - Belo Horizonte, MG - Brasil dos criadouros clássicos (lagoas, valas, córregos, e outros). Foram encontrados caramujos nos pequenos lagos artificiais cimentados de parques, jardins e prédios públicos e em aquários de residências e lojas que vendiam peixes ornamentais, todos localizados em áreas urbanizadas (Guim.:=ães e col., 1990)

iNa presente nota são relatados estudos em uma área de lazer dentro do perímetro urbano de Belo Horizonte e discutidas as causas e importância do aparecimento de moluscos hospedeiros intermediários do $S$. mansoni, neste e em outros locais dentro de áreas urbanizadas das cidades, além de sugerir alguns possíveis mecanismos que podem estar envolvidos com o aparecimento de focos urbanos de esquistossomose.

\section{Material e Método}

Os estudos foram conduzidos no Parque "Julien Rien" (zona sul de Belo Horizonte), de agosto/1983 a agosto/1992. Trata-se de uma área de lazer com $48.500 \mathrm{~m}^{2}$, criada pela Prefeitura Municipal, em encosta arborizada de morro (Figura), em 1980. Por toda a área existem pequenas nascentes (olhos d'água) que têm suas águas coletadas por calhas de cimento $(230,0 \times 0,40 \times 0,20 \mathrm{~m}$ de comprimento, largura e altura, respectivamente) e encaminhadas para um canal cimentado $(26,0 \times 1,70 \times 0,40 \mathrm{~m})$ que recebe também água vinda de uma nascente 


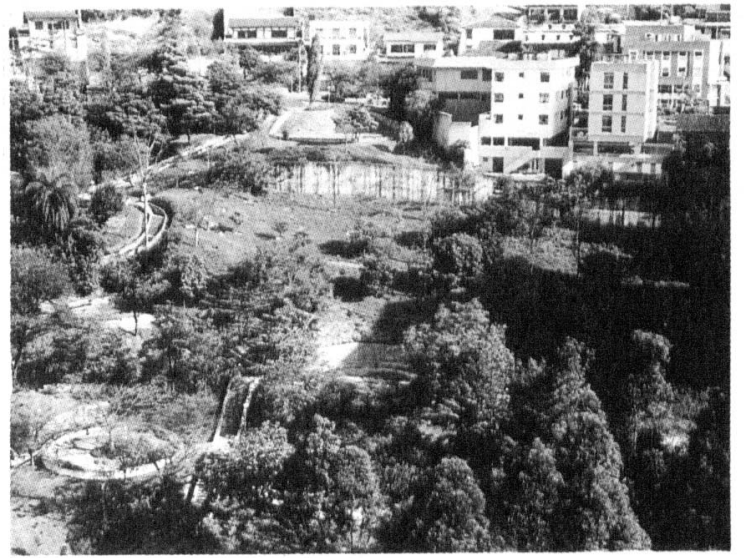

Figura. Parque "Julien Rien": Vista panorâmica (Belo Horizonte, Minas Gerais - Brasil).

maior localizada na parte com mais vegetação do parque. Antes de entrar na rede pluvial, essa água forma uma cascata muito utilizada para banhos, pelos frequientadores do parque, especialmente pelos menores carentes da região periurbana.

Os planorbíneos foram capturados durante todo o decorrer do estudo com pinças metálicas $(18 \mathrm{~cm}$ de comprimento), em pontos adrede demarcados nas calhas de cimento e com conchas metálicas perfuradas $(15 \mathrm{~cm}$ de diâmetro $/ 8 \mathrm{~cm}$ de profundidade), acopladas a cabos de madeira de $1,20 \mathrm{~cm}$ de comprimento, na nascente e no canal cimentado, usando-se o sistema de uma conchada a cada passo. No laboratório os moluscos eram contados, medidos e examinados em microscópio estereoscópio após esmagamento entre placas de vidro. Durante as capturas as temperaturas do ar e da água foram anotadas.

\section{Resultados}

A Tabela mostra que em 28 capturas foram coletados 3.361 exemplares de Biomphalaria glabrata, sendo que $23(0,7 \%)$ albergavam cercárias de $S$. mansoni. O maior número de exemplares capturados em uma visita (749) foi obtido em novembro/89 e a menor amostra (20) em setembro/85. A média do número de exemplares capturados nas 28 coletas foi de 120 com o diâmetro médio das conchas variando de 6,4 $\mathrm{mm}$ (outubro/85) a $12,8 \mathrm{~mm}$ (outubro/87), com média de $9,3 \mathrm{~mm}$.

Não foi encontrada no local nenhuma outra espécie de molusco aquático além da $B$. glabrata, e durante as coletas a tempe.atura do ar variou de $22,0^{\circ} \mathrm{C}\left(4 /\right.$ setembro/84) a $33,0^{\circ} \mathrm{C}$ (11/outubro/85) e a da água de $18,0^{\circ} \mathrm{C}\left(28 /\right.$ junho/85) a $27,5^{\circ} \mathrm{C}(18 /$ dezembro/90).
Tabela. Exemplares de Biomphalaria glabrata capturados e infectados por Schistosoma mansoni no Parque "Julien Rien", Belo Horizonte, Minas Gerais - Brasil (agosto/1983 - agosto/1992).

\begin{tabular}{|c|c|c|c|c|}
\hline \multirow{2}{*}{ Data } & \multicolumn{4}{|c|}{ Exemplares de Biomphalaria glabrata } \\
\hline & Capturados & $\begin{array}{l}\text { Positivos } \\
\text { S. mansoni }\end{array}$ & $\begin{array}{c}\% \\
\text { infecçãa }\end{array}$ & $\begin{array}{l}\text { Diâmetro } \\
(\mathrm{mm}) \bar{x} \pm \mathrm{s}\end{array}$ \\
\hline $77 / a s$ & 26 & 0 & - & $12,5 \pm 3,2$ \\
\hline $24 / a$ & 274 & 6 & 2,2 & $10,6 \pm 4,6$ \\
\hline $16 /$ mai/84 & 114 & 0 & - & $7,4 \pm 2,0$ \\
\hline 04/set/84 & 62 & 0 & - & $6,6 \pm 1,8$ \\
\hline 10/abr/85 & 91 & 0 & - & $7,3 \pm 2,5$ \\
\hline $1 / 85$ & 71 & 0 & - & $10,1 \pm 3,0$ \\
\hline $1 / 85$ & 56 & 1 & 1,8 & $12,2 \pm 3,2$ \\
\hline $02 / j$ & 62 & 1 & 1,6 & $12,3 \pm 2,7$ \\
\hline 16/ago/85 & 30 & 0 & - & $7,6 \pm 1,4$ \\
\hline $20 /$ set/85 & 20 & 0 & - & $6,5 \pm 1,7$ \\
\hline 11/out/85 & 96 & 0 & - & $6,4 \pm 2,2$ \\
\hline 29/abr/86 & 135 & 0 & - & $7,7 \pm 2,4$ \\
\hline 22/out86 & 104 & 2 & 1,9 & $10,8 \pm 2,8$ \\
\hline 29/jan/87 & 72 & 0 & - & $8,6 \pm 2,6$ \\
\hline $21 /$ out 87 & 38 & 0 & - & $12,8 \pm 2,5$ \\
\hline 14/abr/88 & 77 & 0 & - & $8,8 \pm 2,7$ \\
\hline 23/ago/88 & 58 & 1 & 1,7 & $10,4 \pm 2,0$ \\
\hline 17/mai/89 & 84 & 1 & 1,2 & $9,6 \pm 2,8$ \\
\hline 07/nov/89 & 749 & 0 & - & $9,0 \pm 2,6$ \\
\hline 29/mai/90 & 123 & 2 & 1,6 & $11,4 \pm 3,1$ \\
\hline 02/out90 & 245 & 0 & - & $8,5 \pm 2,4$ \\
\hline $18 / \operatorname{dez} / 90$ & 118 & 2 & 1,7 & $10,1 \pm 2,9$ \\
\hline $29 / \mathrm{jan} / 91$ & 205 & 5 & 2,4 & $9,0 \pm 3,1$ \\
\hline $17 / a b r / 91$ & 148 & 0 & - & $7,9 \pm 2,9$ \\
\hline 26/ago/91 & 88 & 0 & - & $9,8 \pm 2,1$ \\
\hline 20/fev/92 & 106 & 2 & 1,9 & $10,4 \pm 3,3$ \\
\hline 17/jul/92 & 81 & 0 & - & $9.0 \pm 2,4$ \\
\hline 17/ago/92 & 28 & 0 & - & $7,3 \pm 3,0$ \\
\hline Tolals & 3.361 & 23 & 0,7 & $9,3 \pm 3,7$ \\
\hline
\end{tabular}

\section{Discussáo}

O encontro de planorbíneos hospedeiros intermediários do $S$. mansoni, em bairros da periferia de Belo Horizonte, é comum e decorre da urbanização ineficiente ou mesmo inexistente nessas áreas, onde são encontrados córregos, lagoas, valas, hortas, e outros, abrigando populaçðes desses moluscos em altas densidades.

Entretanto, o aparecimento de planorbíneos em áreas totalmente urbanizadas nos chamados "criadouros do asfalto" (Guimarães e col. ${ }^{5}, 1990$ ), que são os pequenos lagos artificiais cimentados de parques, jardins e prédios públicos, aquários de peixes ornamentais de residências e de lojas que vendem esses peixes, passa a ser um importante componente no processo de urbanização da esquistossomose.

Ao que as observações sugerem, o aparecimento desses moluscos estaria relacionado com a introdução de plantas aquáticas e peixes nesses locais, conforme já relatado por Correa e col. ${ }^{2}, 1970$. 
Essas introduçōes podem ser acidentais (juntamente com os peixes e/ou plantas aquáticas) ou intencionais feitas por aquariofilistas.

A aquariofilia é uma atividade bastante difundida em Belo Horizonte, sendo comum a manutenção de moluscos nos aquários - especialmente exemplares albinos de $B$. glabrata - como ornamento e também para manter limpos os vidros dos mesmos, já que eles se alimentam das algas que ali se desenvolvem. Esta prática levou, inclusive, alguns proprietários de lojas que vendem peixes ornamentais a criarem esta espécie para vender (Guimarães e col. ${ }^{5}$, 1990). Entretanto, as condições oferecidas pelos aquários favorecem um desenvolvimento muitas vezes exagerado da população dos moluscos e das plantas aquáticas. Quando isto ocorre, eles são eliminados pelo uso de moluscicidas (vendidos pelas próprias lojas) ou o excesso.é retirado dos aquários podendo ser introduzido nas diferentes coleçð̃es hídricas disponíveis (pequenos lagos cimentados de parques, jardins, córregos, lagoas e outros), dentro ou fora da cidade. Processo semelhante ocorre com as plantas aquáticas que podem levar em suas raízes e folhas desovas e/ou moluscos vivos (Correa e col. ${ }^{3}, 1980$ ).

Criado para se constituir em área de lazer e de preservação da flora local, o Parque "Julien Rien" é frequientado por crianças e adolescentes moradores das proximidades e também por menores carentes da periferia da cidade. Em decorrência da presença desses menores, é comum o encontro de fezes humanas na área do parque o que explicaria a captura de exemplares de $B$. glabrata naturalmente infectados pelo $S$. mansoni.

Outro aspecto importante é a topografia do terreno que favorece a manutenção do criadouro durante todo 0 ano sofrendo pouca influência das condiçסes climáticas. A captura feita em 29/ janeiro/91 confirma esta observação pois, ocorrida logo após um intenso período de fortes chuvas, permitiu coletar, sem dificuldades, 205 exemplares de $B$. glabrata dos quais $5(2,4 \%)$ albergavam cercárias do $S$. mansoni (Tabela).

Imediatamente após o primeiro encontro de planorbíneos no Parque "Julien Rien" (outubro/83), a Prefeitura Municipal foi notificada. Em junho e setembro/84 foram feitas aplicações de moluscicida (niclosamida) no local, por técnicos do Centro de Pesquisas "René Rachou" da Fundação Oswaldo Cruz - MG, atendendo pedido da Prefeitura Municipal. Posteriormente ocorreu o repovoamento do criadouro e em junho/92 nova aplicação de moluscicida foi feita. Em 17/agosto/92 foram coletados no local 28 exemplares de $B$. glabrata sem infecção (Tabela).

Além do "Julien Rien" existem mais 5 "parques ecológicos" em Belo Horizonte (Municipal, Man- gabeiras, Cidade Nova, Guilherme Lage e Lagoa do Nado) e projetos da Prefeitura Municipal para a implantação de mais dois (Matinha e Caiçara), em 1992-93. Pesquisas realizadas nesses parques mostraram a ocorrência de $B$. tenagophila (sem infecção) nos parques Municipal, Guilherme Lage e Lagoa do Nado (Guimarães*, 1991). Este último fica próximo à Lagoa da Pampulha, tradicional foco de esquistossomose de Belo Horizonte, onde esta mesma espécie de molusco já foi encontrada naturalmente infectada pelo $S$. mansoni (Carvalho e col. $\left.{ }^{1}, 1985\right)$. Assim, cuidados devem ser tomados para evitar que esses parques também se transformem em focos de esquistossomose.

Dentro deste enfoque, a introdução de peixes e plantas aquáticas nas coleçס̄es hídricas dos parques deve ser evitada. Caso necessário, tanto peixes quanto plantas devem passar por um período de quarentena de no mínimo 30 dias para detecção de desovas e/ou moluscos. A conscientização dos aquariofilistas quanto ao destino a ser dado aos excessos de moluscos e plantas aquáticas dos aquários e uma fiscalização nas lojas para coibir a venda de planorbíneos também devem ser tentadas.

GUIMARÃES. C. T. ei al. [Urban focus of schistosomiasis in metropolitan area in South-eastern Brazil]. Rev. Saúde Pública, 27: 210-3, 1993. Urban focus of schistosomiasis in an urban area of South-eastern, Brazil. An active, urban focus of schistosomiasis in Belo Horizonte, MG, Brazil is described. It is located in the "Julien Rien" Park, a leisure area of $48,500 \mathrm{~m}^{2}$ created by the local administration in 1980 on the south side of city. Snail captures were made over 10 years (19831992) resulting in the collection of 3,361 Biomphalaria glabrata, ranging from 6.4 to $12.8 \mathrm{~mm}$ in diameter (mean $=9.3) ; 23(0.7 \%)$ of these were found to be infected with Schistosoma mansoni. The finding of $S$. mansoni intermediate hosts in urban areas (ponds, small artificial lakes, etc) may be related to the introduction of fish and ornamental aquatic plants coming from specialized shops or areas in which they occur. It is suggested that the introduction of fish aquatic plants into urban water collections without a quarentine period should be avoided, as a prophylactic measure.

Keywords: Biomphalaria, parasitology. Schistosoma mansoni. Schistosomiasis mansoni, transmission. Urbanization.

\section{Referênclas Bibliográficas}

1. CARVALHO, O.S.; GUTMARÃES, C.T.; MASSARA, C.L.; BONÉSIO, J.E.R. Situação atual da esquistossomose

* Dados inéditos. 
mansoni no Lago da Pampulha, Belo Horizonte, MG, Brasil. Rev. Saúde Pública, 19: 270-7, 1985.

2. CORREA, R.R.; MURGEL, J.M.T.; PIZA, J.T.; RAMOS, A.S.; DIAS, L.C.; MORAIS, L.V.C.; ROSÁRIO, F.F. Dispersão de Biomphalaria straminea, hospedeira intermediária do Schistosoma mansoni, através da distribuição đe peixes. Rev. Saúde Pública, 4: 117-27, 1970.

3. CORREA, L.L.; CORREA, M.O.A.; VAZ, J.F.; SILVA, M.I.P.G.; SILVA, R.M.; YAMANAKA, M.T. Importância das plantas omamentais dos aquários como veículo de propagação de vetores de Schistosoma mansoni. Rev. Inst. Adolfo Lutz, 40: 86-96, 1980.

4. COTTA, E. \& MILWARD-DE-ANDRADE, R. A esquistossomose mansoni, Belo Horizonte, MG (Brasil). Situação antiga e atual do problema. Rev. Brasil Malariol. Doenç. Trop., 19: 161-84, 1967.

5. GUIMARÃES, C.T.; SOUZA, C.P.; SOARES, D.M.; ARAUJO, N.; SCHUSTER, L.M.R. Occurrence of moluscs in aquaria of omamental fishes in Belo Horizonte, Minas Gerais, Brazil. Mem. Inst. Oswaldo Cruz, 85: $127-9,1990$.

6. KATZ, N,; MOTTA, E.; OLIVEIRA, V.B.; CARVALHO, E.F. Prevalência de esquistossomose em escolares no Estado de Minas Gerais. In: Congresso da Sociedade Brasileira de Medicina Tropicall14 $4^{e}$ Congresso da So. ciedade Brasileira de Parasitologia, $3^{\circ}$ João Pessoa, 1978. Resumos, João Pessoa, Ed. Universitária UFPb, 1978. p. 102.

7. MARTINS, A.V. \& VERSIANI, W. Schistosomose mansoni em Belo Horizonte. Brasil Médico, 52 (20): 481 . 82, 1938.

8. MARTINS, A.V.; MARTINS, G.; FALCÃO, A.L. Distribuição geográfica dos planorbídeos e seus índices de in. festação pelas cercárias de Schistosoma mansoni no municipio de Belo Horizonte, MG. Apresentado ao Congresso Brasileiro de Higiene, Curitiba, PR, 1953. (mimeografado)

9. MELLO TEIXEIRA, J.A. A schistosomose mansônica na infância em Belo Horizonte. Belo Horizonte, 1919. [Tese de Concurso - Faculdade de Medicina.

10. PAULINI, E.; DIAS, E.P. ; FIUZA, H. Contribuição à epidemiologia da esquistossomose em Belo Horizonte. Rev. Bras. Malariol. Doenç. Trop., 19: 571-606, 1967.

11. SOUZA, C.P.; PEREIRA, J.P.; RODRIGUES, M.S. Atual distribuição geográfica dos moluscos hospedeiros intermediários do Schistosoma mansoni em Belo Horizonte, MG, Brasil. MemInst. Oswaldo Cruz, 76: 383-91, 1981.

Recebido para publicação em 5.11.1992 Aprovado para publicação em 27.5.1993 